\title{
Visual identification of underwater objects using a ROV-type vehicle: "Graf Zeppelin" wreck investigation
}

\author{
Commander Adam Olejnik, PhD. \\ Polish Naval Academy
}

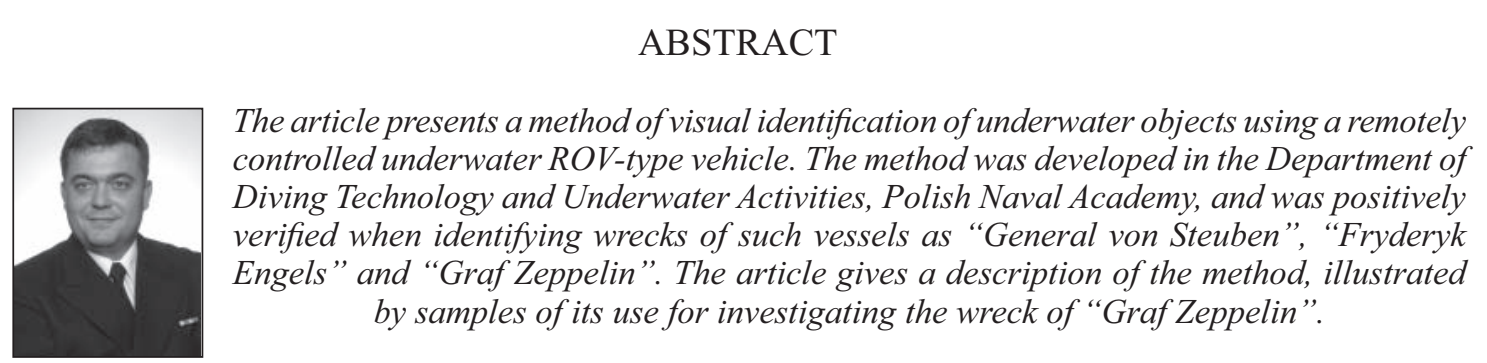

Key words: the wreck of "Graf Zeppelin" as an example of visual identification of underwater objects

\section{INTRODUCTION}

The present-day hydrographic survey equipment offers vast opportunities to investigate various underwater objects, which may even include early detection of the leakage of oil derivatives from tanks situated at the sea bottom [5]. The recording instrumentation and computer software which assist nowadays a hydrographer in his/her work are really impressive, among other opportunities they offer threedimensional visualisation, in the post-processing phase, of the collected measurement data. But despite those facilities and high technical potential, hundred-percent identification of an underwater object still sometimes needs its visual observation. It can be done in a number of ways, out of which hyperbaric methods (with human diving teams), or those making use of unmanned underwater vehicles are most frequently used. As for the hyperbaric methods, diving reconnaissance of objects situated at depths exceeding $50 \mathrm{~m} \mathrm{H}_{2} \mathrm{O}$ may be difficult. A serious difficulty in this case is not only the hydrostatic pressure itself, but also rather a human being with his/her "imperfections". The air, a natural breathing medium, can only be used in diving to the depths not exceeding 50 meters. Deeper underwater activities require a breathing gas with lower specific gravity and different percent share of the oxygen than in the air. Indeed, numerous technologies were developed to allow divers to do their work even as deep as below $300-450$ meters, but these activities are very time-consuming, and, first of all, still extremely expensive. Therefore in identification activities, in which very fast mobilisation or the research team is sometimes required, in particular at depth exceeding 50 meters, unmanned underwater vehicles, most frequently of ROV type (Remotely Operated Vehicle), have been used. This device makes it possible to conduct remote observation of an underwater situation in a close zone of its activity. The range of data collected by the vehicle is only limited by parameters and type of the deck equipment installed on it. Among other instruments it may include a TV camera, a sonar, instruments for measuring hydrological parameters of the water, etc. A big advantage of the ROV is its relatively high mobility and ability to work long hours at high depths, sometimes in extremely difficult conditions. It is essential from the point of view of identification of underwater objects that the examined object can be observed in real time using a remote TV system. The recorded data are transmitted using a so-called control cable (stay cable). It not only secures transmission of the data collected by ROV deck equipment to the operator's station, but is also used for passing commands given by the vehicle operator to steer the motion of the vehicle and the operation of the deck equipment. The above advantages are the reason why the ROV vehicles are so useful, and are most frequently used in underwater work worldwide. Among other reasons, that is why the Laboratory of Unmanned Underwater Vehicles was established in the Department of Diving Technology and Underwater Activities (ZTNiPP), Polish Naval Academy. At present, its basic equipment is "Super Achille", a ROV-type vehicle, made by Comex Pro, France, complemented by the underwater navigation system with the USBL Scout ultra short base, produced by Sonardyne Ltd., United Kingdom, (Fig. 1). The Laboratory has obtained the accreditation of Benhtos Inc, (present name: Teledyne Benthos), USA, and Comex Pro for service and repairs of underwater vehicles produces by these companies. Moreover, as parts of Laboratory's activity, the vehicle repair technology was worked out, along with the methodology of ROV-aided assessment of the technical state of underwater objects, and the methodology of ROV-aided search and identification of underwater objects. These research 
activities were implemented on commission by the Polish Navy, the Ministry of Justice (within the framework of preliminary proceedings in criminal cases, for instance, for Public Prosecutor's Offices in Olsztyn, Mysliborz, and Warsaw), the "Petrobaltic" Oil and Gas Exploration - Production Joint Stock company (evaluation of the technical state of the B3-4BRe borehole installation), and the Polish Navy Hydrographic Office. At present, activities are conducted in the Laboratory, which are oriented on developing a system of real-time three-dimensional visualisation and dimensioning of underwater objects with the aid of a low-cost construction of a small-size ROV-type vehicle. The article presents a methodology, developed in ZTNiPP, of ROV-aided visual wreck identification, complemented by sample results collected during investigations of the wreck of "Graf Zeppelin".

\section{VISUAL WRECK IDENTIFICATION USING A ROV-TYPE VEHICLE}

A detected underwater objects which can create a threat for navigation should be immediately reported to national hydrographic services [2]. In local conditions it means that each newly detected underwater object, which reveals the above features, is reported to the Polish Navy Hydrographic Office.

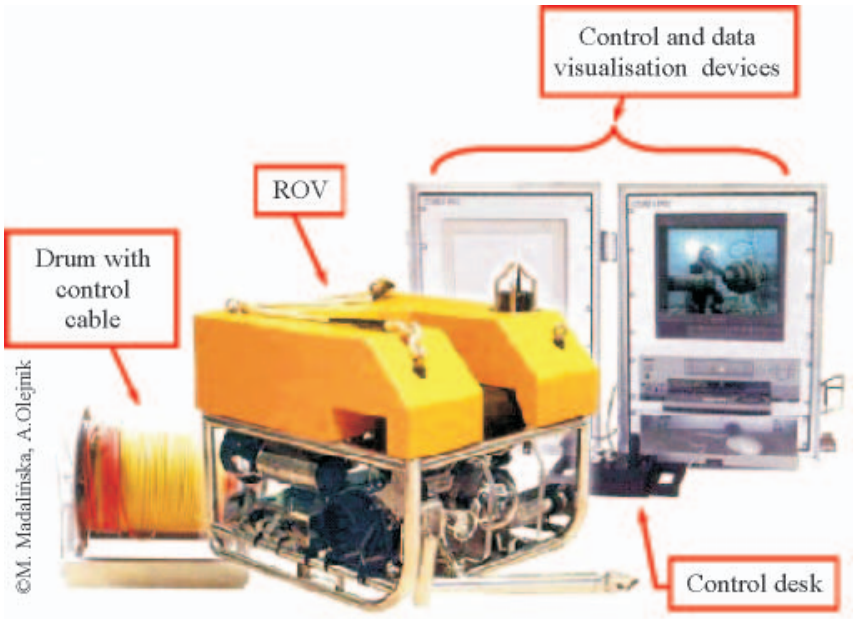

Fig. 1. ROV-type vehicle ,, Super Achille” with basic equipment

This way in July 2006, ORP “Arctowski” was ordered to check the position and dimensions of a large-size underwater object detected by the research ship "St. Barbara". The investigation team was complemented by research workers from the Department of Diving Technology and Underwater Activities, Polish Naval Academy, with ROV as the research equipment (Fig. 1). The task to be done by the investigation team was to take underwater photos of the object and do its visual identification. Usually operations of this type, when conducted with the aid of an underwater vehicle, include the following stages:

$\Rightarrow$ preparing the mission of the vehicle,

$\Rightarrow$ conducting the operating mission of the vehicle,

$\Rightarrow$ processing and analysing the collected data.

\section{Preparing the ROV mission}

This stage is executed before the exit to the region of wreck location. It basically consists in collecting relevant historical material, including photos, pictures, cross-sections, and basic technical data of the hypothetical object (for instance: length, width, number of shaft lines, positions and dimensions of the superstructure, masts, and cargo hatches). Moreover, all data are analysed which were collected during earlier hydrographic measurements.

Based on the above material and its analysis, a method of wreck inspection (vehicle trajectory) is worked out. The adopted method should provide opportunities for collecting the maximum possible volume of camera-recorded data, including characteristic constructional elements of the examined wreck. This stage is very important in the ROV operation, as the collected material should make the basis for wreck identification. At the same time the analysis of the information collected during hydrographic measurements in the past should result in working out the strategy of vehicle approach to the wreck, and selecting a relevant configuration of the vehicle - control cable arrangement. These issues will be discussed in detail in the section describing the operating mission of the vehicle.

\section{ROV operating mission}

The operating mission of the vehicle is prepared based on all information collected so far, and the data recorded during the hydrographic measurements [6]. Firstly, we select a configuration of the control cable - vehicle system, and then we select for the ROV a method how to approach the wreck. The configuration of the control cable - vehicle system depends on the depth at which the wreck is located [3,7]. When the examined object is at the depth ranging between 20 and 40 meters, the most convenient way is to use a floating cable as a stay cable to avoid trimming. We should remember, however, to avoid situations in which the floating stay cable, of a considerable length, floats freely in the depths of water behind the vehicle. In this case the operator cannot control its shaping, which can provoke hooking of the cable to the wreck construction, or cable damage. If it happens, we can swim along the cable until we reach the point of hooking and then analyse the situation on-site. Sometimes a sufficient remedy to free the vehicle is to do some simple manoeuvres. When this fails, we should drive the vehicle to the surface over the wreck structure, as far as the cable permits. Most frequently in these situations, a loop formed around a mast, for instance, will rise over its construction and free the vehicle. In extreme cases, a diving team is to be involved to free the vehicle. In such a case we loosen the cable to the maximum on the drum and drive the vehicle to the surface, to the minimum possible depth (preferably to the non-decompression zone). When the divers start diving, the ROV supply is to be switched off to allow the diver safely approach the vehicle and disconnect the control cable [8]. Then the cable can be pulled out by winding it onto the drum. In an extreme case when the cable cannot be pulled out, we take the risk to lose the cable but we still can get back the vehicle, the most expensive system component. At higher depths, ranging between 40 and 120 meters, a useful method is to use a combined stay cable, consisting of the floating segment and the non-floating segment. This configuration of the control cable - vehicle system is shown in Fig. 2. This solution reminds a traditional method of circular search in diving techniques. The non-floating cable segment, directed vertically down to the depth at which the wreck is situated, is mounted to the loaded descending line, while the floating segment plays a role of the distance line.

The operating mission of the vehicle at depths exceeding 120 meters can be most safely conducted using a so-called underwater garage. The underwater garage is a structure reminding a metal cage with a cable drum. When inside this cage, the vehicle is safely transported from the deck of the base craft (understood as the vessel/ship from which the vehicle is 


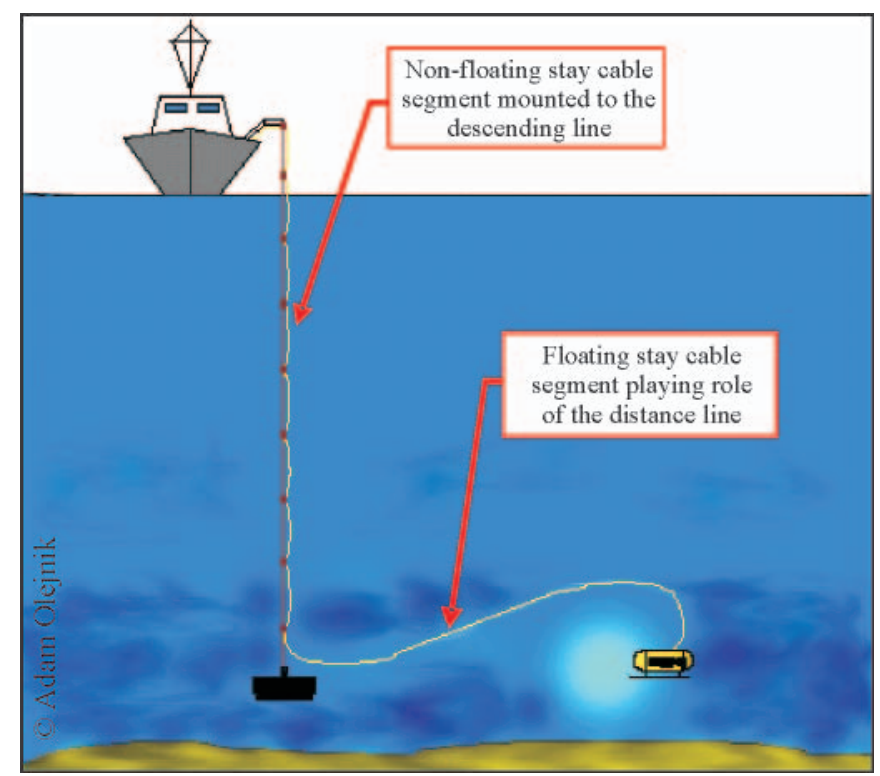

Fig. 2. The control cable - vehicle arrangement for depths ranging between 40 and 120 meters [8]

operated) to the level of wreck location. And only when it reaches this level, the vehicle leaves the garage and starts its operating mission, which first of all consists in safe approach to the wreck. After selecting the control cable - vehicle arrangement we can start submerge the vessel in the water. In this case, however, when there is no access to the underwater garage, it is advisable to do first the reconnaissance of the possible ROV approach trajectory to the bottom. Among other factors, its necessity results from the fact that sonar visualisation usually does not take into account nets nor cables/ropes surrounding the wreck. The trajectory of vehicle approach to the bottom in the area or close vicinity of the examined object can be recognised using an underwater TV camera lowered vertically down to the bottom. Using this camera, the situation along the vehicle submersion trajectory can be visualised, which facilitates assessing the type and scale of possible threats. Even if, for various reasons, the camera is damaged or lost, this loss is incomparably less expensive than possible loss of the vehicle. When submerging, the vehicle can crash into protruding construction elements of the examined object (masts, smokestacks), or get immobilised when the vehicle propulsion system gets entangled in parts of the nets surrounding the wreck, in particular in fishing areas. Sometimes lack of this reconnaissance may lead to an accident. A situation of this type took place when identifying the wreck of "Goya" using a small-size ROV vehicle named "Gnom" [6]. After its propellers had got entangled in the nets the vehicle was totally immobilised. An attempt to free it by a team of divers ended with their death.

The reconnaissance is done immediately after the base vessel is anchored. It is noteworthy that the position of base vessel anchorage is usually a compromise between its safety and operating abilities of the underwater vehicle. It happens very rarely that the captain of the ship from which the vehicle is operated agrees to anchor directly over the wreck. In all other cases, taking into account ship safety we should select the anchoring position in such a way as to provide opportunities for the vehicle to approach the examined object from the direction opposite to that defined by its masts and/or smokestacks. After recognising the trajectory of vehicle submersion, the operation can start. When the vehicle reaches the bottom of the sea, it should be directed towards the examined object. The way in which the vehicle approaches the examined object depends on its deck equipment and abilities of the used homing systems. Wreck approaching over a so-called oval wreckage field cannot be used in the Baltic Sea, as this phenomenon occurs at much higher depths than those recorded in this water region $[1,8]$. The oval wreckage filed is created when the ship sinks and all heavy constructional elements fall down almost vertically, while the lighter parts are convected by underwater currents and drop slower. As a consequence, when the distance to the bottom is sufficiently large, these light elements are spread over a relatively large area. On the Baltic Sea small wreckage fields can be observed in the vicinity of wrecks, or characteristic bottom material corrugation resulting from the impact of the sinking ship into the bottom [5]. All this is the effect of a relatively low depth, on average, of the water region, in which the sinking ship is sometimes longer than the depth at which is sinks.

In case of the simplest control cable-vehicle arrangement the ROV is directed towards the wreck using indications of the deck sonar mounted on the vehicle.

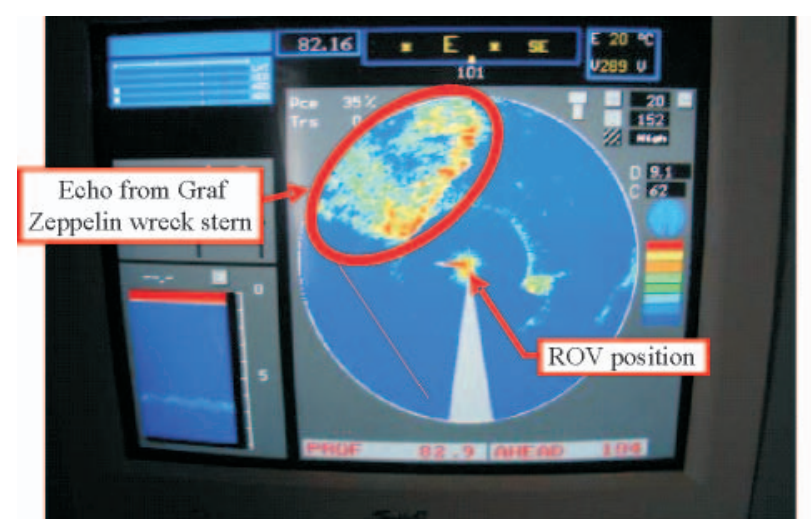

Fig. 3. ROV service desk in operation: sonar screen. Echo from the stern of the examined underwater object and vehicle position with respect to it are clearly visible (photo: S. Lipinski)

When submerging the vehicle we stop it at a distance of about 1,5 meters from the bottom surface and do the sonar reconnaissance around the vehicle (Fig. 3). The above task is quite easy if the vehicle is equipped with an all-round sonar, as in this case it will be able to visualise the situation within the angle of $360^{\circ}$ in the vicinity of the vehicle. By recording the strongest and the weakest echo on the sonar we obtain the information on the course and distance of the wreck from the current position of the vehicle. When the ROV does not have such a sonar, the water region should be scanned in parts to collect this information. Keeping it at one place, we rotate the vehicle several times by $90^{\circ}$ and analyse the sonar screen. Homing the vehicle to the wreck can be made easier by the use of an underwater navigation system, which allows the information on the current underwater position of the ROV vehicle with respect to the wreck position to be recorded. The underwater navigation system makes use of the network of acoustic transponders. Depending on the positions of the transponders and the distance between them, three types of systems can be named:

with a long base line (LBL),

$>$ with a short base line (SBL),

$>$ with an ultra short base line (USBL).

In ZTNiPP the Scout-type USBL system is used, basic components of which are shown in the figure below.

The USBL system makes use of a hydroacoustic transponder, mounted on the ROV, and the head with a series of transmitters and receivers. The vehicle position is calculated from a series of measurements consisting in determining the distance between the head and the transponder. A converter mounted on the ROV transmits the signal to the head, which, among other things, 
measures the time between the signal transmission and the reception of the return signal. The measured time, along with the known speed of sound, make the basis for calculating the distance from a given transponder. A collection of results of these measurements, combined with the geographic position of the transmitting/receiving head, known from the DGPS receiver and treated as the vehicle position, are displayed on the monitor screen of the underwater navigation system (Figs. 4 and 5).
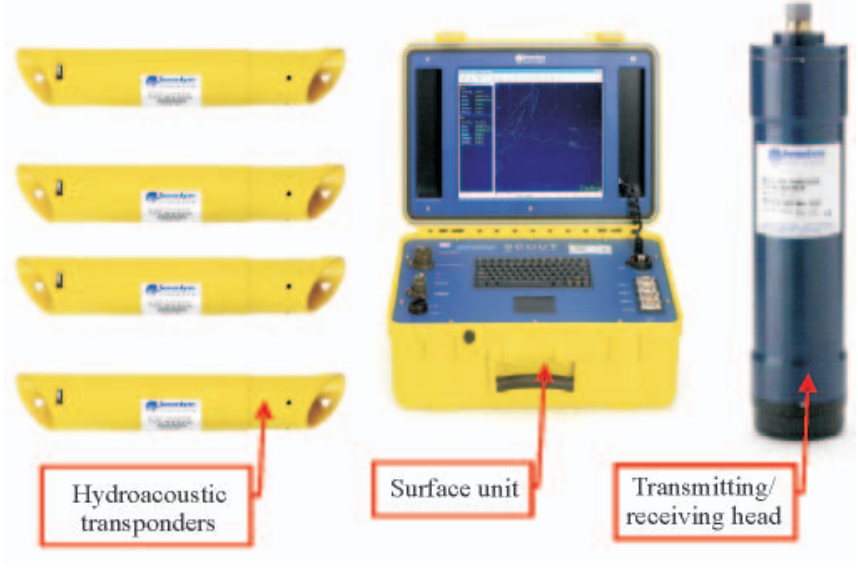

Fig. 4. Producer's set of the USBL Scout system

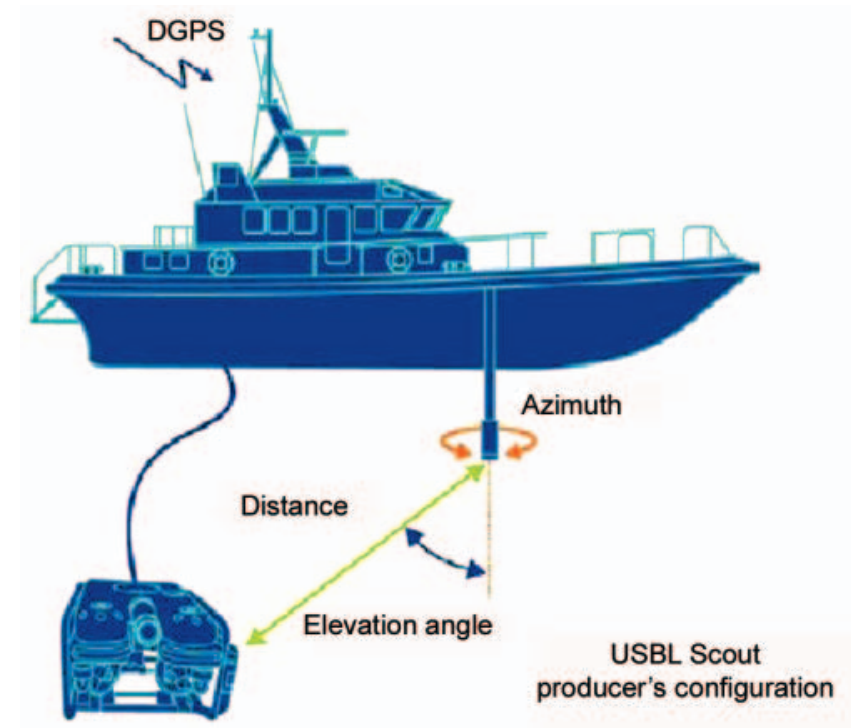

Fig. 5. Principle of USBL system operation [11]

Since ZTNiPP operates from various base ships, sometimes also on inland water regions, it turned out necessary to work out and produce a design which would allow the research team to become independent of watercraft type, in order to make full use of the owned USBL system. For this purpose a special measuring buoy was built (Fig. 6). The buoy consists of a mast and displacement floats. On its underwater part the transmitting/ receiving head of the USBL Scout system is mounted, while on the top of the mast the DGPS receiver is installed to read geographic coordinates of the buoy position. The assembly of the DGPS receiver and the USBL Scout head on one mast (in one axis) eliminates the need for measuring the distance and relative positions of these two devices, along with storing these data in the memory of the USBL system.

The last stage of the operating mission of the vehicle is covering the planned trajectory within the wreck structure. Each time the route should be started from the ship's side and from the bottom level. This procedure allows avoiding any damages, which could possibly result from a collision

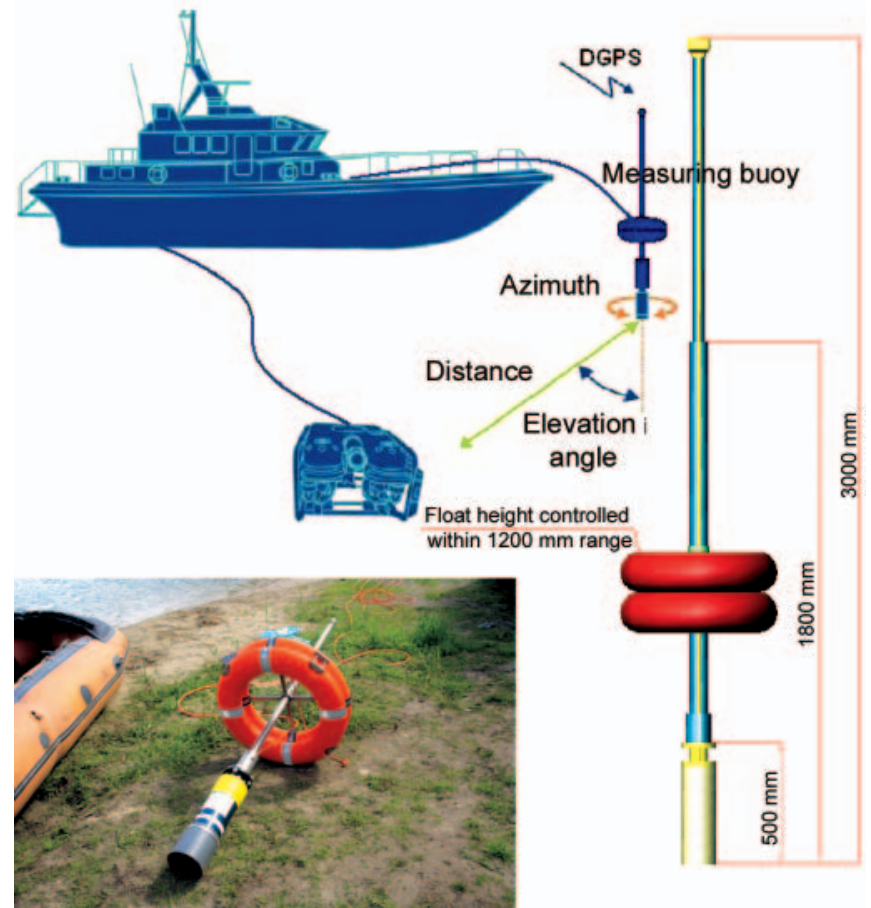

Fig. 6. USBL Scout system configuration, worked out in ZTNiPP and making use of the measuring buoy

with the wreck structure due to small space visualised by the camera mounted on the vehicle and insufficient, as a rule, information on the real structure of the wreck. In cases of any identification research, it is most likely the first time for years or even decades when the wreck is observed within a visible band. That is why the reconnaissance is to be started from the bottom level, and the vehicle is to be directed along the ship's side toward the surface, to the level of the main deck. When in there, the vehicle should move in parallel to the ship's side and search for characteristic constructional elements. The passing trajectory over the wreck should provide opportunities for filming most representative material, based on which wreck identification and verification could be done. Each recorded detail (shape of the superstructure, number and distribution of portholes, number of davits, position and size of holds, positions of navigation lamps, number of shaft lines, supporting bearings, etc.) will increase chances for positive verification. An ideal solution is reading the name of the ship written on its side of stern, but it happens rather rarely and refers to wrecks which do not stay long on the bottom. In case of older objects this is less likely due to intensive hull covering with a growth. When the wreck of the "Graf Zeppelin" aircraft carrier was identified, a number of vehicle dives were done from the deck of ORP „Arctowski” to the depth of about 90 meters. During these dives the vehicle covered the trajectory shown in Fig. 7. As a result, about 3,5-hour material was recorded on the film and then used for comparison with the historical material. The next figure presents selected film frames extracted from the above video material.

\section{Processing and analysing of the collected data}

When the operating mission of the vehicle ends, we can proceed to processing and analysing the collected data. This is a so-called post-processing stage, in which we make use of all data collected so far on the examined object, and compare them with the archival material. The best way in this case is to use relevant computer software to extract individual frames from the film and process them digitally. If, during the 


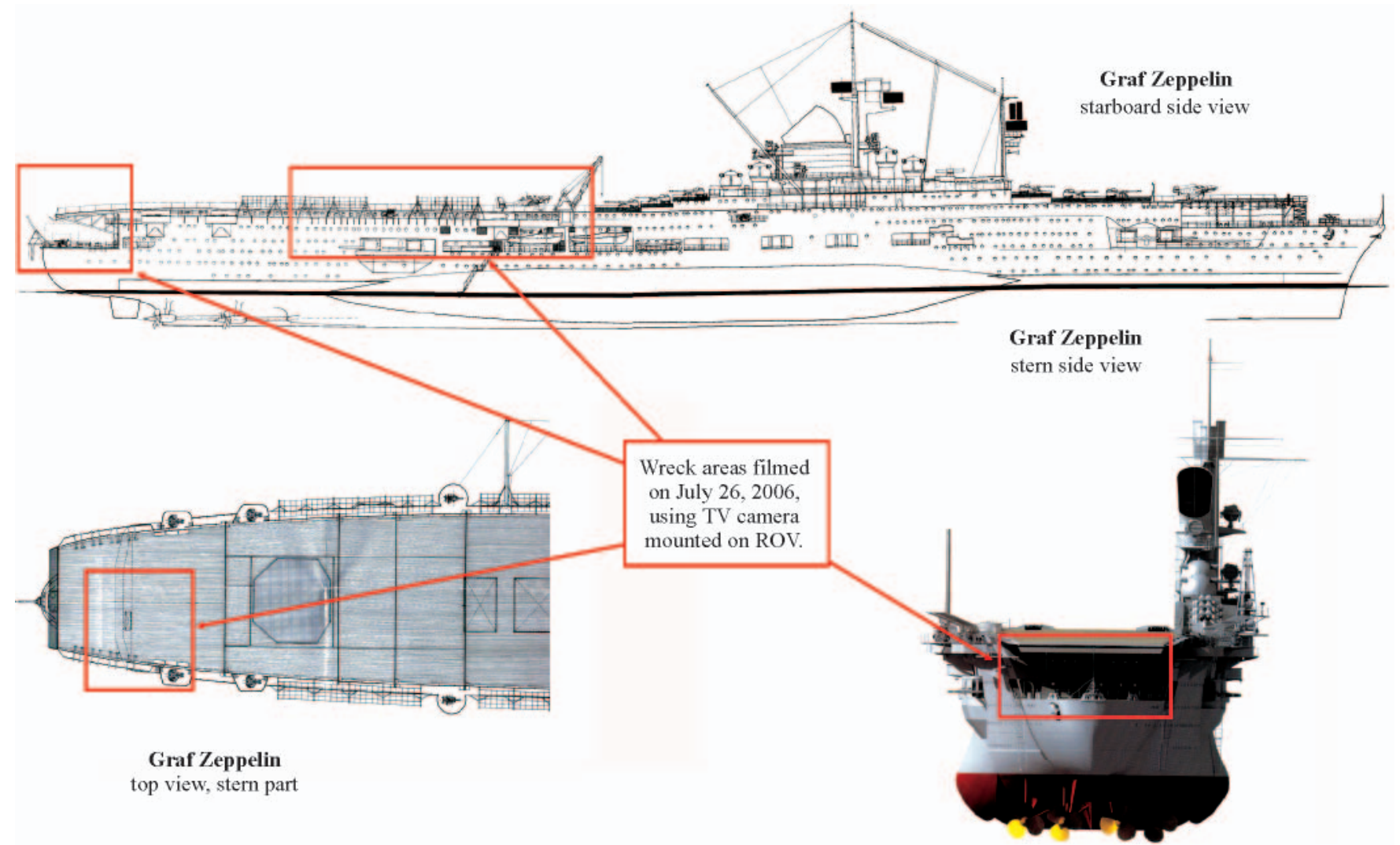

Fig. 7. ROV trajectory during identification of the "Graf Zeppelin" wreck [4, 9]
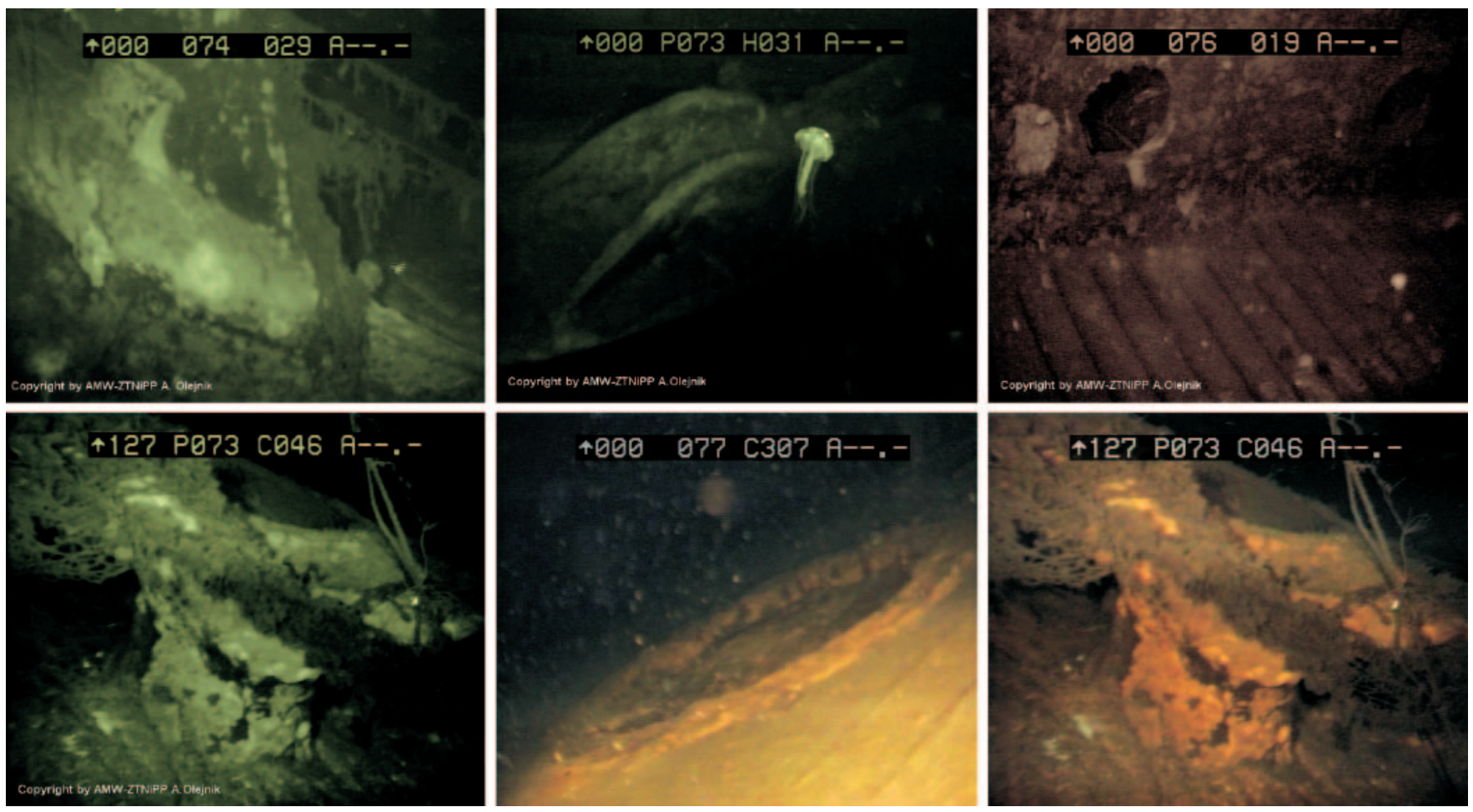

Fig. 8. Selected photos presenting wreck of "Graf Zeppelin". Photos were recorded using ROV [author's investigations]

operating mission, we did not store a digital version of the film recorded by the TV camera mounted on the vehicle, the first step after completing the mission is to copy the film to a digital carrier. Then the entire material is checked, frame-byframe, looking for pictures which can be compared with the archival material. If we find such a frame, we extract it from the film as a separate photo file, magnify it and compare with the magnified part of a photo of drawing of the ship before its sinking. As for the "Graf Zeppelin" wreck, the comparison material was taken from a cyclic publication "Encyclopaedia of battleships" published by the AJ-Press Publishing House in Gdansk, volume 42 of which, worked out by S. Breyer, was devoted to this ship and included a series of detailed drawings and visualisations of the $3 \mathrm{D}$ construction of the ship. Authors of the drawings were S. Breyer, J. Jackiewicz, K. Kania, M. Skwiot and K. Żurek [4]. The drawings were made based on shipyard plans, photos and other historical documents on the "Graf Zeppelin". Having collected all the comparison 

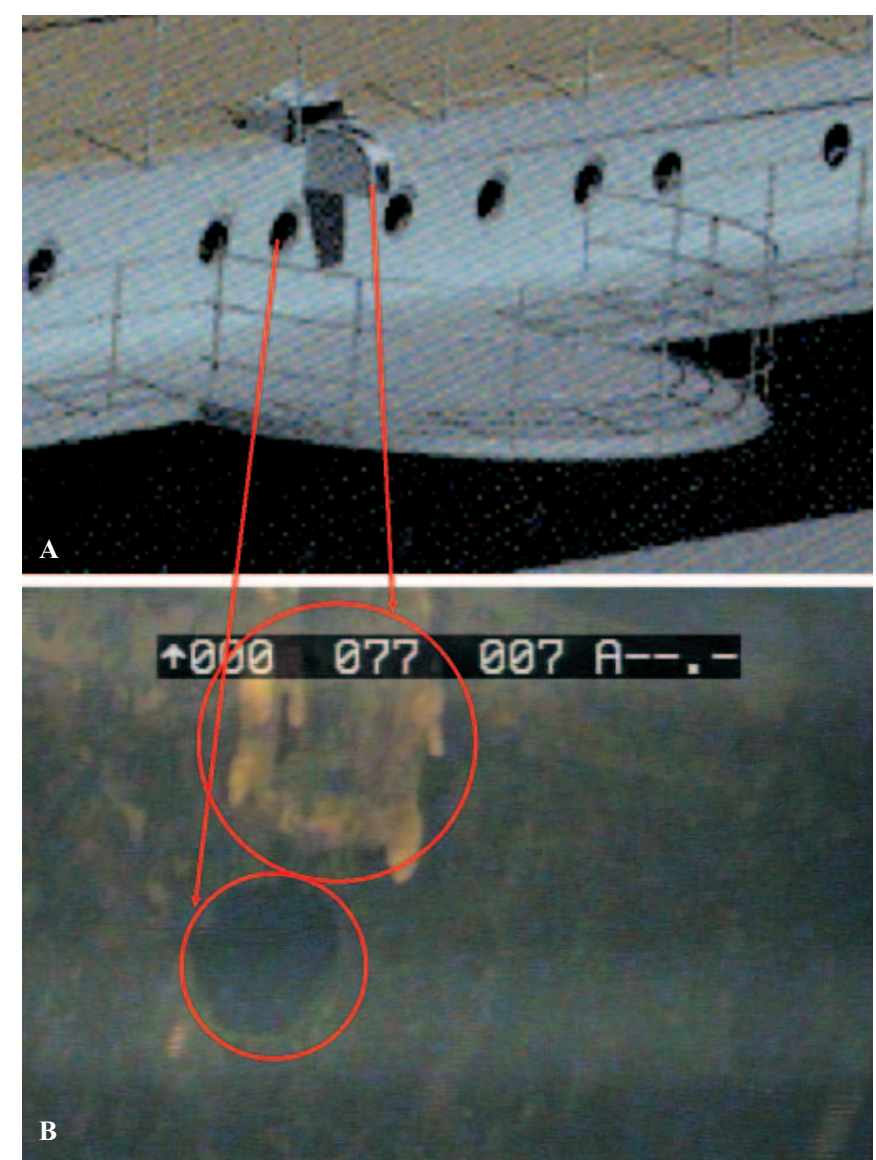

Fig. 9. Comparing material collected using ROV (B) with that presented in Breyer's publication (A): visible clear correspondence between two constructional elements with respect to their shapes and relative positions $[4,9]$. material, the ship identification is done by comparing the selected film frames with relevant material presenting the ship before sinking. The more details can be matched, the higher is the probability of wreck identification. A collective analysis of the abovementioned drawings, photos and film frames, taking into account the order of filming of particular wreck elements and logical succession of appearance of fragments in accordance with the source material allows a conclusion to be made that in all probability the wreck filmed on July 26, 2006, is the German aircraft carrier "Graf Zeppelin". The figures below present selected fragments from the document entitled "Analysis of the film material recorded using the ROV vehicle during the inspection of the underwater object Graf Zeppelin", prepared for the Navy Hydrographic Office as a report from the identification activities.

\section{SUMMARY}

The above-presented method of visual identification of underwater objects was developed as a result of realisation of various orders for research services. Author's personal experience gained in the past was used for its preparation, along with the information obtained during various trainings in the field of: underwater navigation (Sonardyne Sea Trials Center, Plymouth, United Kingdom), use of unmanned vehicles in underwater work technologies (Lerici International Winter School on Marine Technologies, Lerici, Italy) and operation of ROV vehicles (Comex Pro, Marseille, France). The method was positively verified during search and verification works, commissioned by the Polish Navy Sea Rescue Command Centre (search for Su-22, Baltic Sea), identifying wrecks of "Fryderyk Engels", "Steuben", and "Graf Zeppelin" (commissioned by: Polish Navy Hydrographic Office) and numerous activities on inland water regions, for instance search for the body of

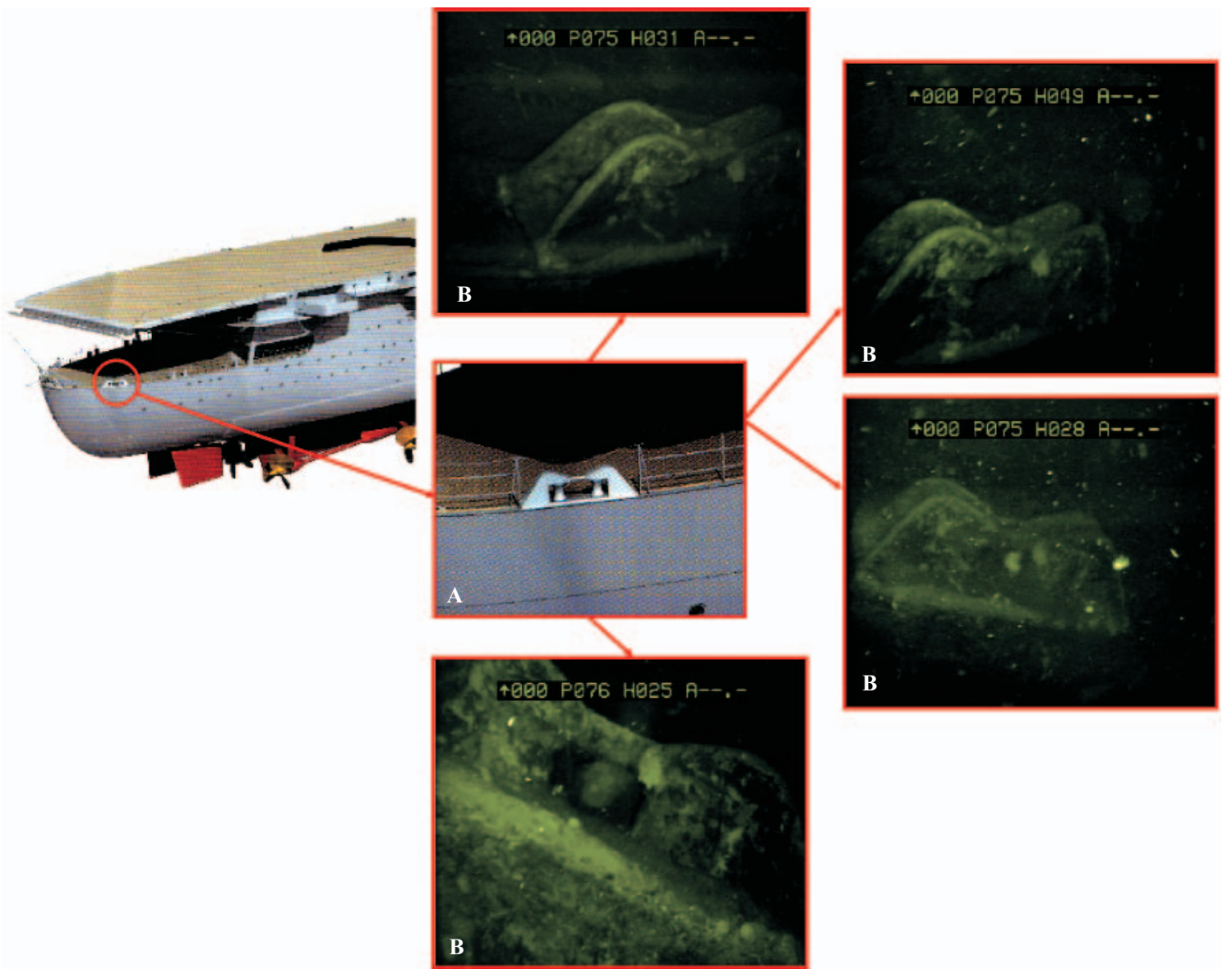

Fig. 10. Comparing material collected using ROV (B) with that presented in Breyer's publication (A) [4,9] 

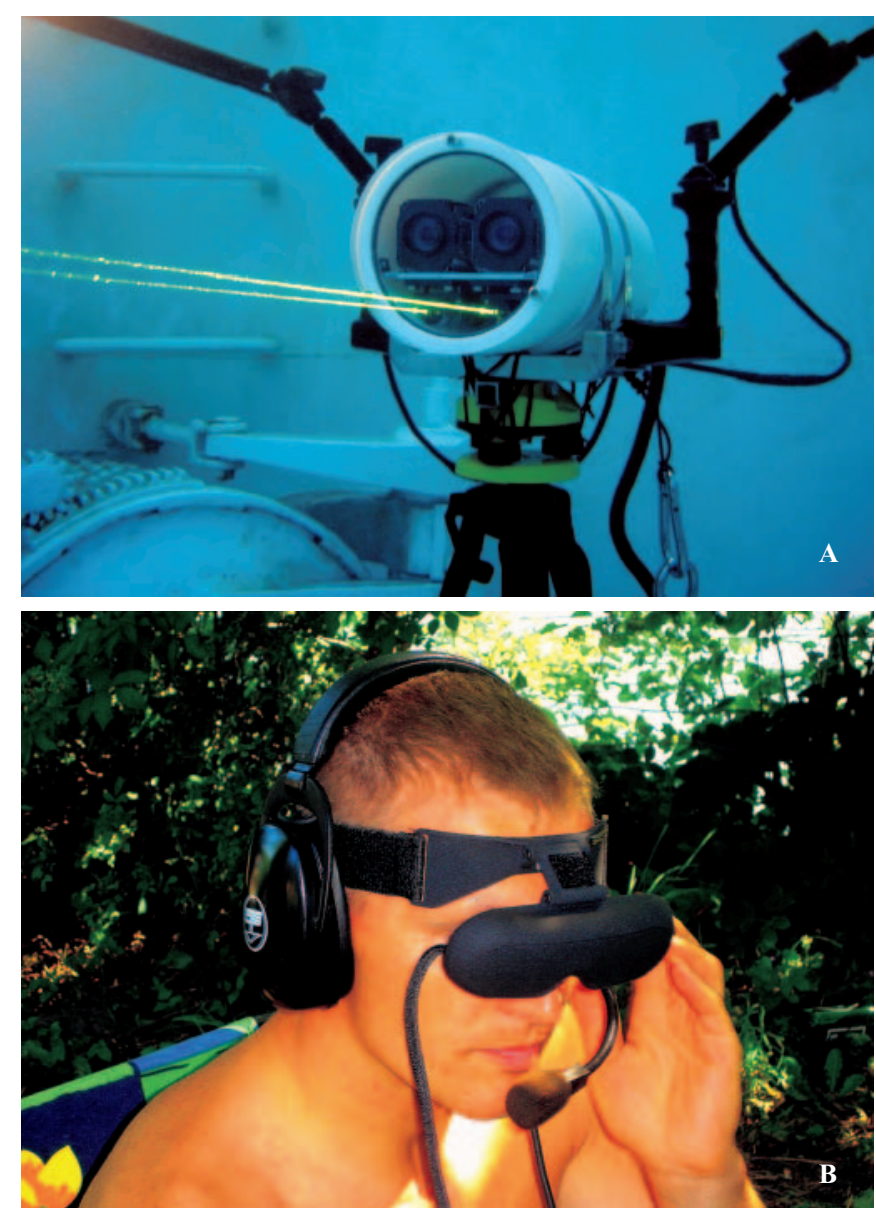

Fig. 11. System of three-dimensional visualisation of underwater objects. A-underwater part of the system during basin tests, two-camera system of picture acquisition in DVD quality, laser subsystem for placing background points to the frame to allow its scaling and dimensioning, $B$-element of surface part of the system-subsystem for head-located visualisation, operator is equipped with special goggles and receives a non-compressed picture from two cameras, to each eye separately [13]

a diver in Lake "Ciecz" (commissioned by: PSP Headquarters of the Poviat of Swiebodzin). It is noteworthy that during the identification of the "Steuben" wreck, for instance, these activities were conducted after supposed wreck discovery by the National Geographic team operating from a German vessel "Fritz Reuter". However wreck characteristics indicated by them, along with the general technical state, strongly suggested that their identification was incorrect and that was another object. After some time National Geographic finally admitted that the first team to discover the "Steuben" wreck was that of Polish Navy, in particular the Polish Navy Hydrographic Security Unit (dZH MW), that carried on all hydrographic work $^{1}[10,12]$. Within the framework of these activities, Polish Naval Academy (more precisely: the Department of Diving Technology and Underwater Activities) was responsible for minor part connected with visual identification of the wreck, done using ROV. The above cooperation and experience gained when applying the developed identification methodology made it possible to formulate a conclusion that the proposed methodology, complemented with a wide variety of presentday hydrographic methods, provides wide opportunities for full identification of an underwater object without the presence of a diving team. A practical depth limit to which the above method can be used is only defined by the length of the vehicle control cable. Indeed, the method is not ideal and has its drawbacks. For instance it does not allow dimensioning of the filmed objects and comparing these dimensions with historical data, which would possibly lead to more precise and unique identification. This drawback is connected with the use of a common TV standard, i.e. single-screen visualisation. This visualisation method loses perspective in the picture, with resultant inability to recognise general shapes of the observed objects and their relative positions in space. That is why in the ZTNiPP Unmanned Vehicle Laboratory, activities are in progress over a system of stereoscopic real-time visualisation of underwater objects, with their simultaneous dimensioning and scaling, done using computer aided photogrammetric methods. The effect of remote three-dimensional real-time visualisation was obtained using a two-camera picture acquisition system and special goggles with liquid-crystal screens (Fig. 11) [13].

The prototype, which has been built so far, is under preliminary tests. Further work will be oriented on improving the present design and determining its metrological characteristics. As a final goal, its is intended to be a visual system mounted on the ROV-type vehicle, design assumptions of which have already been worked out. Moreover, a demonstration model of the vehicle has was built and preliminary tests were conducted on depths down to 16 meters in laboratory and real conditions (Figs. 12 and 13).

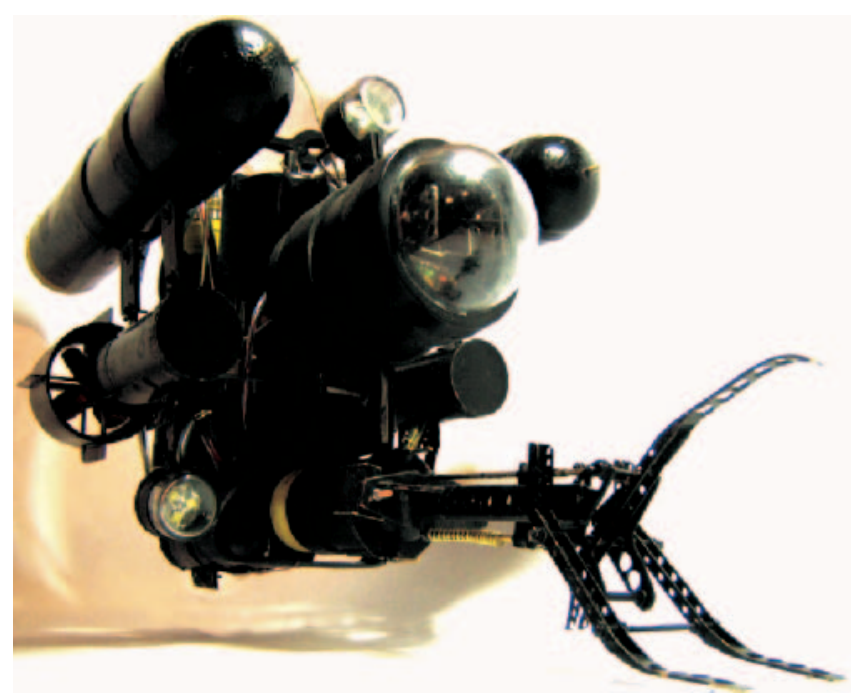

Fig. 12. Mini ROV "Gammarus": developed and built construction

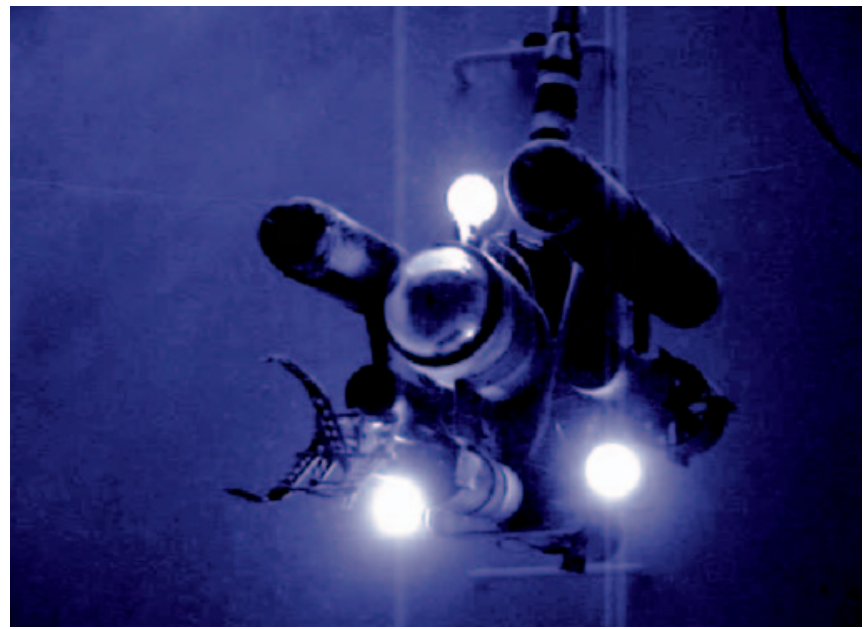

Fig. 13. Mini ROV “Gammarus” in underwater position 


\section{Acknowledgements}

The author thanks the AJ-Press publishing house, Gdansk, for their agreement to use "Graf Zeppelin" drawings published as: Siegfried Breyer: "Graf Zeppelin" ISBN 83-7237156-3; Gdańsk 2004, in the series entitled „Encyclopaedia of Battleships" Volume 42. Moreover, the author thanks the crews of ORP „Heweliusz" and „Arctowski" ${ }^{3}$ for their cooperation and assistance during the research work.

\section{BIBLIOGRAPHY}

1. Ballard R. D.: “Quests”, Bellona Publishers, Warszawa 2000, (in Polish)

2. Beczek D. Grządziel A., Banaszak M., Kłosiński A., Olejnik A.: "Examining the wreck of the aircraft carrier "Graf Zeppelin" using present-day hydroacoustic and visual hydrographic means"; Proceedings of the 15-th International Scientific and Technical Conference on "The Role of Navigation in Support of Human Activity on the Sea" Naval Academy, Gdynia 2006 (in Polish)

3. Bell Ch., Bayliss M., Warburton R. "Handbook for ROV pilot/ technicians" Oilfield Publications Inc. USA, 2006

4. Breyer S. "Graf Zeppelin" Encyclopaedia of Battleships (42), AJ - Press Publishing House, Gdańsk 2004 (in Polish)

5. Dyrcz Cz., Grabiec D., Olejnik A.: "Identifying the "Engels" wreck - sample use of the potential of present-day hydrographic equipment for examining wrecks and sea impurities" Marine Conference on "Aspects of surface water and underwater safety, and flights over the sea" Gdynia 2004 (in Polish)

6. Grabiec D., Olejnik A. "Search and identification of underwater objects" in: "Wrecks of Baltic Sea - manual for divers" collective work, edit. St. Poleszak, Series: Books for Divers, Gdynia 2005, (in Polish)

7. Last G., Williams P. "An introduction to ROV operations" Oilfield Publications Inc. USA 2006

8. Olejnik A. "Methodology of search for underwater objects in seal and inland conditions with the use of unmanned vehicles" Polish Hyperbaric Research, 2005 (in Polish)

9. Olejnik A. "Analysing photo material collected by ROV during inspection of the underwater object "Graf Zeppelin", Naval Academy, Gdynia 2006 (in Polish)

10.Pomian I. "Sensation in the depths of Baltic Sea" National Geographic, No. 7 (2004), (in Polish)

11. Collective work: "USBL Scout - Operation manual" Sonardyne Ltd. WB 2005

12.Collective work: "Steuben. Last big discovery in Baltic Sea?" Diving Magazine, No. 8 (2004) (in Polish)

13.Collective work, edit.: A.Olejnik "System of three-dimensional visualisation of underwater objects, Stage II. Building and tests of the system” Statute work directed by „Narval”, Polish Naval Academy, Gdynia 2006, (in Polish).

\author{
CONTACT WITH THE AUTHOR \\ Commander Adam Olejnik, PhD. \\ Institute of Ship Construction and Operation \\ Department of Diving Technology \\ and Underwater Activities \\ Polish Naval University \\ Śmidowicza 69 \\ 81-103 Gdynia POLAND \\ e-mail: aolej@wp.pl
}

${ }^{2}$ Captain: Commander Marek Czarnecki (in years 2002 - 2007), at present Commander Grzegorz Kokosiński

${ }^{3}$ Captain: Commander Dariusz Beczek (in years 2003 - 2007), at present Commander Artur Grządziel

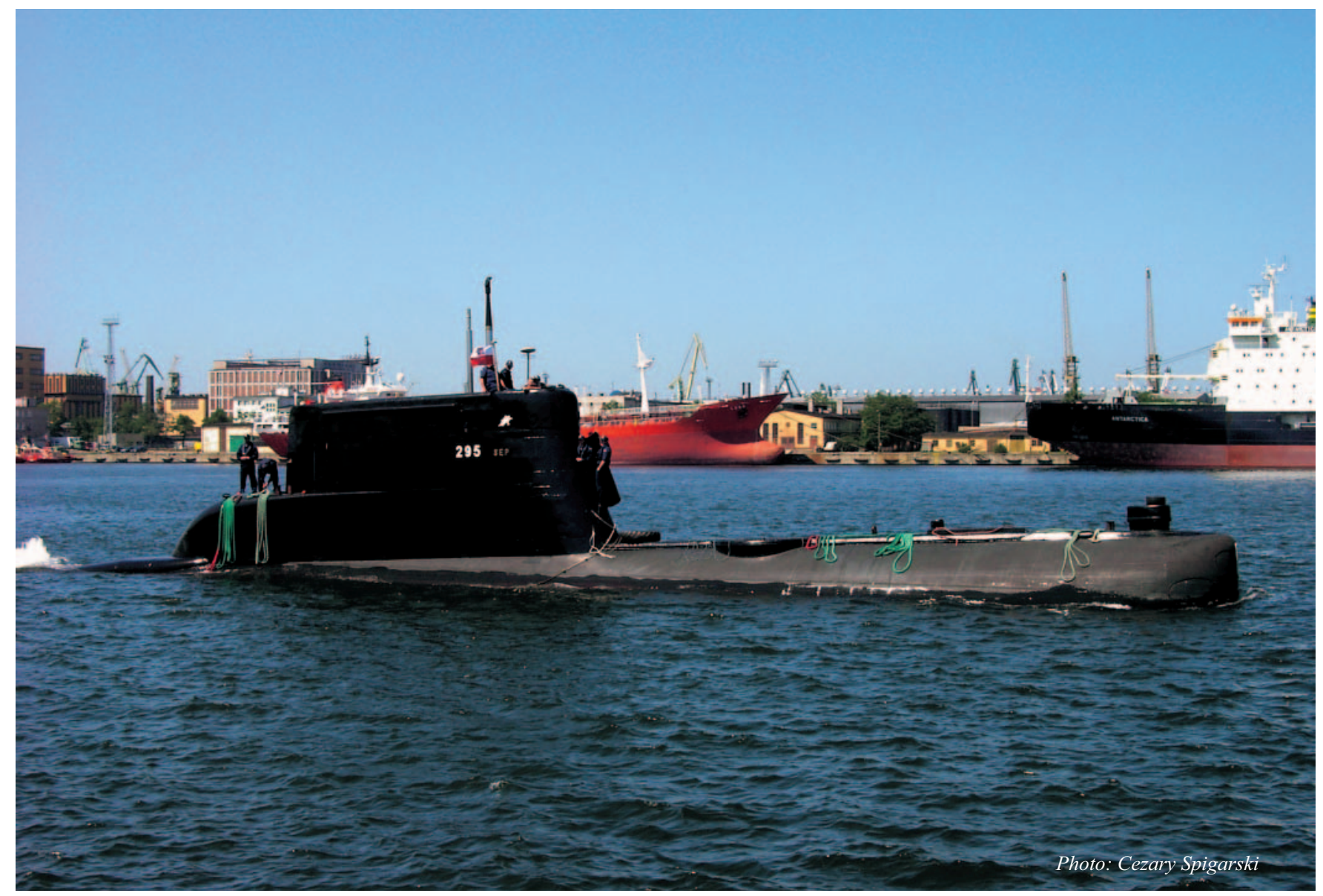

